\title{
Autophagy-lysosomal defect in human CADASIL vascular smooth muscle cells
}

\section{Hanemaaijer, Evelyn S.}

2018-11

Hanemaaijer , E S, Panahi , M , Swaddiwudhipong , N, Tikka , S, Winblad, B , Viitanen , M , Piras , A \& Behbahani , H 2018 , ' Autophagy-lysosomal defect in human CADASIL vascular smooth muscle cells ' , European Journal of Cell Biology , vol. 97 , no. 8 , pp. 557-567 . https://doi.org/10.1016/j.ejcb.2018.10.001

http://hdl.handle.net/10138/307690

https://doi.org/10.1016/j.ejcb.2018.10.001

publishedVersion

Downloaded from Helda, University of Helsinki institutional repository.

This is an electronic reprint of the original article.

This reprint may differ from the original in pagination and typographic detail.

Please cite the original version. 
Research paper

\title{
Autophagy-lysosomal defect in human CADASIL vascular smooth muscle cells
}

\author{
Evelyn S. Hanemaaijer ${ }^{\mathrm{a}}$, Mahmod Panahi ${ }^{\mathrm{a}}$, Nol Swaddiwudhipong ${ }^{\mathrm{a}}$, Saara Tikka ${ }^{\mathrm{c}, \mathrm{d}}$, \\ Bengt Winblad $^{\mathrm{a}}$, Matti Viitanen ${ }^{\mathrm{b}}$, Antonio Piras ${ }^{\mathrm{a}, *, 1,2}$, Homira Behbahani ${ }^{\mathrm{a}, *, 1}$ \\ ${ }^{a}$ Division of Neurogeriatrics, Center for Alzheimer Research, Department of Neurobiology, Care Sciences and Society, Huddinge, Sweden \\ ${ }^{\mathrm{b}}$ Division of Clinical Geriatrics, Center for Alzheimer Research, Department of Neurobiology, Care Sciences and Society, Huddinge, Sweden \\ ${ }^{\mathrm{c}}$ Medicum, Biochemistry/Developmental Biology, Meilahti Clinical Proteomics Core Facility, University of Helsinki, Helsinki, Finland \\ ${ }^{\mathrm{d}}$ Folkhälsan Institute of Genetics, Helsinki, Finland
}

\section{A R T I C L E I N F O}

\section{Keywords:}

VSMC

LC3

Lysosomes

CADASIL

Autophagy

\begin{abstract}
A B S T R A C T
Cerebral autosomal dominant arteriopathy with subcortical infarcts and leukoencephalopathy (CADASIL) is a familial progressive degenerative disorder and is caused by mutations in NOTCH3 gene. Previous study reported that mutant NOTCH3 is more prone to form aggregates than wild-type NOTCH3 and the mutant aggregates are resistant to degradation. We hypothesized that aggregation or accumulation of NOTCH3 could be due to impaired lysosomal-autophagy machinery in VSMC.

Here, we investigated the possible cause of accumulation/aggregation of NOTCH3 in CADASIL using cerebral VSMCs derived from control and CADASIL patients carrying $N O T C H 3^{R 133 C}$ mutation. Thioflavin-S-staining confirmed the increased accumulation of aggregated NOTCH3 in VSMC ${ }^{\mathrm{R} 133 \mathrm{C}}$ compared to VSMC ${ }^{\mathrm{WT}}$. Increased levels of the lysosomal marker, Lamp2, were detected in $\mathrm{VSMC}^{\mathrm{R} 133 \mathrm{C}}$, which also showed co-localization with NOTCH3 using double-immunohistochemistry. Increased level of LC3-II/LC3-I ratio was observed in VSMC ${ }^{\text {R133C }}$ suggesting an accumulation of autophagosomes. This was coupled with the decreased co-localization of NOTCH3 with LC3, and Lamp2 and, further, increase of p62/SQSTM1 levels in VSMC ${ }^{\mathrm{R} 133 \mathrm{C}}$ compared to the VSMC ${ }^{\mathrm{WT}}$. In addition, Western blot analysis indicated phosphorylation of p-ERK, p-S6RP, and p-P70 S6K. Altogether, these results suggested a dysfunction in the autophagy-lysosomal pathway in $\mathrm{VSMC}^{\mathrm{R} 133 \mathrm{C}}$.

The present study provides an interesting avenue of the research investigating the molecular mechanism of CADASIL.
\end{abstract}

\section{Introduction}

Cerebral autosomal dominant arteriopathy with subcortical infarcts and leukoencephalopathy (CADASIL), an inherited small vessel disease, is characterized by neurological signs such as strokes, migraine with aura and cognitive impairment (Dichgans et al., 1998). Pathological characteristics in CADASIL brain are deposits of granular osmiophilic material (GOM) in close vicinity to the basement membrane of small diameter arterioles, and degeneration of vascular smooth muscle cells (VSMCs) (Ruchoux et al., 1994; Ruchoux and Maurage, 1997). VSMC degeneration occurs with subsequent massive fibrotic thickening of the vessel walls (Miao et al., 2004) and narrowing of the lumina of small penetrating arterioles in cerebral white matter.
The onset of CADASIL is from 25 to 60 years-of-age with recurrent strokes leading to progressive cognitive decline and finally to dementia. The correct diagnosis of CADASIL patients is difficult since most patients initially experience migraine with aura that is often miss-diagnosed as migraine. The disease is caused by mutations in the NOTCH3 gene (Joutel et al., 1996); therefore the gold standard for diagnosis of CADASIL is genetic testing. Furthermore, white matter changes observed via magnetic resonance imaging (MRI) are a characteristic feature of CADASIL that have been utilized as an indication of the disease. The pathological characteristic deposits; GOM, have also been observed extracellularly in skin, retina, muscle (Ruchoux et al., 1994), which have also functioned as additional standard for diagnosis of CADASIL by electron microscopy. Up to now there are no clinical tests that can be

\footnotetext{
* Corresponding authors at: Karolinska Institutet, Dept. of NVS, Center for Alzheimer Research, Div. of Neurogeriatrics, Novum 5th floor, SE-141 57, Huddinge, Sweden.

E-mail addresses: antonio.piras@astrazeneca.com (A. Piras), homira.behbahani@ki.se (H. Behbahani).

${ }^{1}$ Co-last authors.

${ }^{2}$ Current address: AstraZeneca, Innovative Medicines \& Early Development, RIA, SE-431 83, Mölndal, Sweden.
} 
taken readily and inexpensively in helping for diagnosis of CADASIL.

NOTCH3 is a member of the NOTCH receptor family, which is expressed in arterial VSMCs and pericytes (Joutel et al., 2000, 1996; Prakash et al., 2002). Members of this type I transmembrane protein family (Andersson et al., 2011; Artavanis-Tsakonas et al., 1999) share structural characteristics that include an extracellular domain (ECD) with a large number of tandemly organized epidermal growth factorlike (EGF) repeats, a transmembrane spanning sequence, and an intracellular domain (ICD) (Borggrefe and Oswald, 2009; Wang et al., 2002). There are at least 230 CADASIL causing mutations, which are located within the EGF repeats, and almost all lead to the change in number of cysteine residues from even to odd (Tikka et al., 2014). These mutations may have various functional consequences on the NOTCH3 receptor, including abnormal folding or dimerization, impairment of interaction with its ligands, and aberrant interaction with other proteins (Joutel et al., 1997). The unpaired cysteine residues can prompt mutated NOTCH3 ${ }^{\mathrm{ECD}}$ to fold abnormally (Opherk et al., 2009) or bind to another cysteine-containing protein (Arboleda-Velasquez et al., 2011). Indeed, accumulation of NOTCH3 ${ }^{\mathrm{ECD}}$ has been found on the surface of VSMCs and in the deposition of GOM (Ishiko et al., 2006). Further, proteomic analysis of human brain vessels carrying the CADASIL mutation, identified clusterin and collagen $18 \alpha 1$ /endostatin as GOM components linking to hypomorphic NOTCH3 function (Arboleda-Velasquez et al., 2011; Joutel et al., 2000). Also, in different experimental system and pathological investigations on patient derived tissues, mutated NOTCH3 receptors appears to misfold and form intracellular aggregates (Karlstrom et al., 2002; Takahashi et al., 2010). It is not clear whether formation of intracellular NOTCH3 aggregates is a result of impaired NOTCH3 intracellular trafficking and maturation or defects in lysosomal clearance process. Therefore, it is likely that CADASIL represents another example of a misfolded protein disorder.

The mutant N-terminal sequences of NOTCH3 has influenced processing and function of its expression in the cytoplasm (Karlstrom et al., 2002). Previous studies showed that the degradation of ICDs of NOTCH1 and NOTCH4 is controlled by the ubiquitin-proteasome system (UPS), though more recent work demonstrated that NOTCH $1^{\mathrm{ICD}}$ is also controlled by lysosomal degradation (Jia et al., 2009).

Autophagy impacts VSMCs survival and function. There are three different ways through which endogenous proteins and particles can be delivered to the lysosome for degradation: chaperon-mediated autophagy (CMA), microautophagy and macroautophagy (Ciechanover, 2005). Macroautophagy (hereafter called autophagy) is capable of degrading aggregations, and is therefore a rather interesting candidate for the degradation of aggregated NOTCH3 (Ciechanover and Kwon, 2015). Alterations in autophagy has been documented in VSMC in response to various stimuli, resulting in modulation of VSMC functions, including proliferation, migration, matrix secretion, contraction/relaxation, and differentiation (Tai et al., 2016). Each of these changes in VSMC functions plays a critical role in the development of vascular diseases. Importantly, emerging evidence demonstrates that autophagy deficiency in VSMCs would contribute to atherosclerosis and restenosis, shedding novel light on therapeutic target of the vascular disorders (Tai et al., 2016). Deficits in the autophagy-lysosomal pathway result in protein aggregation, generation of toxic protein species, and accumulation of dysfunctional organelles, which are hallmarks of many neurodegenerative disorders (Ciechanover and Kwon, 2015; Martini-Stoica et al., 2016; Zhang et al., 2009).

While there have been studies on the topic of NOTCH3 ${ }^{\mathrm{ECD}}$ aggregations, few studies investigated whether accumulation/aggregation and degradation of intracellular mutated NOTCH3 in CADASIL. In this report, we investigated the autophagic-lysosomal pathway in CADASIL by studying lysosome numbers, and localization of NOTCH3 in lysosomes as well as autophagosomes. In addition, we have also studied a few proteins involved in the signal pathway of ERK/MAPK related to autophagy function. We used a cell line of cerebral VSMCs origin from CADASIL patients carrying NOTCH $3^{\mathrm{R} 133 \mathrm{C}}$ mutation and healthy control and discuss the implications of these findings for the pathogenesis of CADASIL.

\section{Material and methods}

\subsection{Cell lines}

Patient-derived cerebral arterial VSMC $\left(\mathrm{VSMC}^{\mathrm{R} 133 \mathrm{C}}\right)$ as well as control VSMC $\left(\mathrm{VSMC}^{\mathrm{WT}}\right.$ ) cell lines were established from post mortem subarachnoidal branches of cerebral arteries (human cerebral arterial VSMC) (Gimbrone et al., 1974; Ihalainen et al., 2007; Tikka et al., 2012). CADASIL patients and control subjects were genetically verified by the presence or absence of mutations as previously described (Panahi et al., 2018).

The ethical permission of human VSMCs carrying mutation and controls has been approved from the Ethical Board of the Hospital District of Varsinais-Suomi and Turku University Hospital, the National Authority for Medicolegal Affairs in Finland, and by the regional Ethical review board of Stockholm, Sweden (Dnr: 2016/1275-31/4).

\subsection{Cell culture}

The $\mathrm{VSMC}^{\mathrm{WT}}$ and $\mathrm{VSMC}^{\mathrm{R} 133 \mathrm{C}}$ were grown in DMEM/Nutrient Mixture F-12 with GlutaMAX (Thermo Fisher Scientific, U.S.A.), supplemented with $10 \%$ heat inactivated fetal bovine serum (HI-FBS, Gibco, Invitrogen), and Penicillin-Streptomycin $(100 \mathrm{U} / \mathrm{mL} / 100 \mu \mathrm{g} /$ $\mathrm{mL}$ ) at $37^{\circ} \mathrm{C}$. Cells were cultured continuously under standard cell culture conditions and passaged every $2-3$ days.

\subsection{Treatments}

$\mathrm{VSMC}^{\mathrm{WT}}$ and $\mathrm{VSMC}^{\mathrm{R} 133 \mathrm{C}}$ were treated with chloroquine (CQ) ( $25 \mu \mathrm{M}$; Sigma Aldrich) diluted in complete medium at variant time points. CQ inhibits lysosome protein degradation by increasing lysosome $\mathrm{pH}$, which inhibits its proteolytic enzymes and causes the accumulation of autophagic vacuoles (Geng et al., 2010; Wibo and Poole, 1974). CQ concentrations were based on values presented by a previous report (Jia et al., 2009).

\subsection{Real time quantitative $R T-P C R$}

$\mathrm{VSMC}^{\mathrm{WT}}$ and $\mathrm{VSMC}^{\mathrm{R} 133 \mathrm{C}}$ were grown overnight in a 6-well plate chamber with confluence of 100.000 cells. The following day, the cells were lysed with RIPA buffer (ThermoFisher Scientific, U.S.A.) and the quality of RNA was determined with RIN (RNA Integrity Number) of 10. cDNA was prepared using Taqman gene expression master mix (Applied Biosystem) and SuperScript VILO cDNA Synthesis kit (ThermoFisher Scientific, U.S.A.) according to the manufacturer's protocol. Quantitative (q) RT-PCR was performed using costume format TaqMan fast plate (Applied Biosystems). All probes were used in duplicates with $30 \mathrm{ng}$ of cDNA. Quantitative RT-PCR was performed on a 7500 Fast Real-Time PCR System (Life Technologies, U.S.A.). The expressions of genes were normalized to internal control HPRT gene and analysis was used comparing the normalized value of VSMC ${ }^{\mathrm{WT}}$ cell line to the normalized values of $\mathrm{VSMC}^{\mathrm{R} 133 \mathrm{C}}$ cell line. All the quantitative data were from three independent biological replicates for each experiment and the control value was normalized to 1 .

\subsection{Immunohistochemical analyses}

\subsubsection{NOTCH3 single staining and confocal analysis}

The cultured VSMC ${ }^{\mathrm{WT}}$ and $\mathrm{VSMC}^{\mathrm{R} 133 \mathrm{C}}$ were washed twice with phosphate buffered saline (PBS) and fixed with 4\% paraformaldehyde (Sigma Aldrich) for $10 \mathrm{~min}$ at room temperature (RT). After fixation the samples were washed with PBS, and treated with $0.2 \%$ Triton X-100 in PBS for 20 min at RT. The cells were then washed again with PBS and 
incubated with $1 \%$ bovine serum albumin (BSA; Sigma Aldrich) for $30 \mathrm{~min}$. Then the cells were washed again with PBS and incubated with Protein block serum (DAKO) for $15 \mathrm{~min}$ at RT to block unspecific binding sites. Following incubation with primary human anti-NOTCH3 that target the C-terminus of NOTCH3 (ICD) (Santa Cruz Biotechnology, [M20], dilution 1:250) overnight $(\mathrm{ON})$ at $4{ }^{\circ} \mathrm{C}$, the cells were washed with PBS and blocked with 3\% normal goat serum in PBS for 15 min at RT. Later the cells were incubated with the secondary antibody Alexa Fluor 488-conjugated anti-goat IgG (Invitrogen; dilution 1:800) for $1 \mathrm{~h}$ at RT in $0.2 \%$ Triton X-100/3\% normal goat serum. A cell sample incubated with only secondary antibodies was used as a negative control. After the staining, the cells were washed, fixed and mounted using VECTASHIELD mounting medium with DAPI (Vector Laboratories Inc). All immunofluorescent imaging was performed of a Zeiss META LM510 system. We have only used NOTCH3 antibodies that recognized the $\mathrm{C}$ terminus of NOTCH3 (ICD) in this study.

\subsection{NOTCH3 aggregations}

Immunocytochemistry and confocal analyses was performed to investigate intracellular aggregation of NOTCH3 in $\mathrm{VSMC}^{\mathrm{R} 133 \mathrm{C}}$ and VSMC $^{\text {WT }}$. Briefly, the cultured VSMCs were washed twice with PBS and fixed with $10 \%$ formalin solution (Sigma-Aldrich) for $5 \mathrm{~min}$ at RT. Following washing with PBS, the cells were stained with thioflavin $S$ (Thio-S) $(1 \mathrm{mg} / \mathrm{mL}$ or $3 \mu \mathrm{M})$, diluted 1:50 in PBS, for $5 \mathrm{~min}$ at RT. For co-staining with NOTCH3 antibody, the VSMC ${ }^{\mathrm{R} 133 \mathrm{C}}$ and $\mathrm{VSMC}^{\mathrm{WT}}$ were incubated with $0.3 \%$ Triton X-100 diluted in PBS for 20 min at RT for permeabilization. After washing with PBS, the blocking step was carried out by incubating the cells for $30 \mathrm{~min}$ with $1 \%$ bovine serum albumin (BSA, Sigma) diluted in PBS. The cells were then incubated over night with primary antibodies; NOTCH3 (ICD) (Santa Cruz Biotechnology, A-6, 1:250 dilutions) at $4{ }^{\circ} \mathrm{C}$. The following day, the samples were washed 3 times with PBS and incubated for $1 \mathrm{~h}$ with the secondary antibody; Alexa Fluor 546 donkey anti-mouse, (Invitrogen, 1:400 dilution). After washing with PBS, the samples were mounted with mounting medium containing DAPI (Vector Laboratories Inc). All immunofluorescent imaging was performed of a Zeiss META LM510 system.

\subsection{NOTCH3 and Lamp2}

For co-localization of NOTCH3 with lysosomes, the VSMC ${ }^{\mathrm{WT}}$ and $\mathrm{VSMC}^{\mathrm{R} 133 \mathrm{C}}$ were stained with mouse Lamp2 antibody (abcam, dilution 1:200) to visualize the lysosomes, and co-stained with NOTCH3 (ICD) antibody (Santa Cruz Biotechnology, M20, dilution 1:250). VSMCs were exposed to CQ and incubated for different incubation times $(0,1,4$, and $24 \mathrm{~h}$ ). After staining, the VSMCs were washed, fixed and mounted as described above.

\subsection{NOTCH3 and p62/SQSTM1}

For co-localization of NOTCH3 with autophagy marker, the $\mathrm{VSMC}^{\mathrm{WT}}$ and VSMC ${ }^{\mathrm{R} 133 \mathrm{C}}$ were stained with anti-p62/SQSTM1 antibody (Cell Signalling, rabbit, 1:300 dilutions), and NOTCH3 (ICD) (Santa Cruz Biotechnology, mouse clone: A-6, 1:250 dilutions). The staining procedure was done as described above. After staining, the VSMCs were washed, fixed and mounted as described above.

\subsection{NOTCH3 triple-staining with lysosomal and autophagy markers}

For co-localization of NOTCH3 with lysosomal and autophagy markers, before and after treatment, triple immunostaining was also performed. The VSMC ${ }^{\mathrm{WT}}$ and VSMC ${ }^{\mathrm{R} 133 \mathrm{C}}$ were treated with CQ for $24 \mathrm{~h}$. The staining procedure was done as described above. The antibodies used for triple staining were: anti-LC3 (NB100-2331, Novus Biotechnology; dilution 1:200), anti-Lamp2 (Lysosome-associated membrane protein 2) (ab25631, Abcam; dilution 1:200), and antiNOTCH3 (Santa Cruz Biotechnology, clone. M20) followed by incubation with secondary antibodies Alexa Fluor 633-conjugated anti-rabbit (Invitrogen; dilution 1:500), and Alexa Fluor 546-conjugated, antimouse (Invitrogen; dilution 1:200), and Alexa Fluor 488-conjugated anti-goat.

Images were acquired using a Zeiss META LM510 system. Analysis of the images was carried out using the "Analyse Particles" function on the software ImageJ.

\subsection{Quantification of triple staining}

The number of lysosomes in $\mathrm{VSMC}^{\mathrm{WT}}$ and $\mathrm{VSMC}^{\mathrm{R} 133 \mathrm{C}}$ quantified prior to and after CQ-treatment. Approximately 20 VSMCs were counted for each sample. For the autophagosomes, first the LC3-positive dots were counted, and then LC3-positive dots that co-localized with NOTCH3 and Lamp2, or LC3-Lamp2-NOTCH3 were calculated.

\subsection{Western blotting}

The untreated and CQ-treated VSMC ${ }^{\mathrm{WT}}$ and VSMC ${ }^{\mathrm{R} 133 \mathrm{C}}\left(3.0 \times 10^{5}\right.$ cells/well) were grown to $70 \%$ confluence. Then, the VSMCs were washed twice with PBS, collected and lysed by lysis buffer $(0.65 \%$ NP40, $10 \mathrm{mM}$ Tris $\mathrm{pH} 8.0,1 \mathrm{mM}$ EDTA, $150 \mathrm{mM} \mathrm{NaCl}$ ) containing protease inhibitors (Mammalian ProteaseArrest; G-Biosciences). Samples were incubated on ice for $15 \mathrm{~min}$, with a ten second vortex interval every two min. Cell debris was cleared by centrifugation at 13 $200 \mathrm{rpm}$ for $10 \mathrm{~min}$ at $4^{\circ} \mathrm{C}$. The samples were concentrated through rotary evaporation. Total protein content was measured using the Pierce BCA Protein Assay Kit (Thermo Scientific). Total protein extracts (10-25 $\mu$ g) were mixed with $2 \times$ SDS sample buffer (Sigma Aldrich), boiled for $5 \mathrm{~min}$ and loaded onto NuPAGE $4-12 \%$ or $12 \%$ Bis-Tris (Life Technologies) using NuPAGE MES or MOPS SDS Running Buffer (Life Technologies). Gels were blotted with the wet tank transfer system (Hoefer) using Amersham Protran $0.45 \mu \mathrm{m}$ Nitrocellulose membrane (GE Healthcare Life Sciences) and transfer buffer (20 mM Tris-HCl pH 8.6, $120 \mathrm{mM}$ glycine, $20 \%$ methanol). The membranes were blocked using 5\% milk (Semper) in TBS-T (20 mM Tris pH 7.5, $150 \mathrm{mM} \mathrm{NaCl}$, $0.1 \%$ Tween 20). After two TBS-T washing steps the membranes were incubated over night at room temperature or $4{ }^{\circ} \mathrm{C}$ with the primary antibodies (see Table 1 ) diluted in $5 \%$ milk and $0.2 \%$ sodium azide. The membranes were washed with TBS-T and incubated with specific secondary antibodies, anti-rabbit and anti-mouse IgG conjugated with horseradish peroxidase (HRP; GE Healthcare) for $1 \mathrm{~h}$, at RT. Using

Table 1

List of primary antibodies used for western blot (WB) and immunofluorescence (IF) techniques.

\begin{tabular}{lllll}
\hline Antigen & Host & Dilution & Source & WB vs. IF \\
\hline ERK & Mouse & $1: 1000$ & BD Biosciences & WB \\
pERK & R1abbit & $1: 1000$ & Cell Signalling Technology & WB \\
mTOR & Rabbit & $1: 1000$ & Cell Signalling Technology & WB \\
pmTOR & Rabbit & $1: 1000$ & Cell Signalling Technology & WB \\
S6 RP & Mouse & $1: 1000$ & Cell Signalling Technology & WB \\
pS6 RP & Rabbit & $1: 1000$ & Cell Signalling Technology & WB \\
P70 S6K & Rabbit & $1: 1000$ & Cell Signalling Technology & WB \\
pP70 S6K & Rabbit & $1: 1000$ & Cell Signalling Technology & WB \\
p62/SQSTM & Rabbit & $1: 1000$ & Cell Signalling Technology & IF/WB \\
LC3 & Rabbit & $1: 2000$ & Cell Signalling Technology & WB \\
LC3 & Rabbit & $1: 200$ & Novus Biotechnology & IF \\
Lamp1 & Mouse & $1: 500$ & Santa Cruz Biotechnology & WB \\
Lamp2 & Mouse & $1: 200-1: 500$ & Abcam & IF/WB \\
GAPDH & Mouse & $1: 1000$ & Sigma-Aldrich & WB \\
NOTCH3 & Goat & $1: 250$ & Santa Cruz Biotechnology & IF \\
NOTCH3 & Mouse & $1: 250$ & Santa Cruz Biotechnology & IF \\
NOTCH3 & Rabbit & $1: 1000$ & Cell Signaling Technology & WB \\
Ubiquitin & Rabbit & $1: 500$ & Enzo Life Sciences & WB \\
& & & &
\end{tabular}




A
\begin{tabular}{|l|l|l|}
\hline Gene name & RQ & Protein Name \\
\hline NOTCH3-Hs01128537_m1 & 2.7941 & NOTCH3 \\
\hline NOTCH3-Hs01128537_m1 & 2.525 & NOTCH3 \\
\hline
\end{tabular}

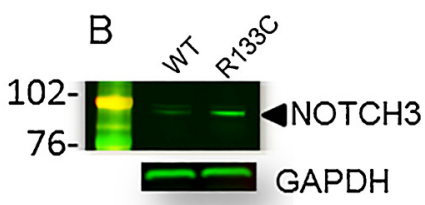

C
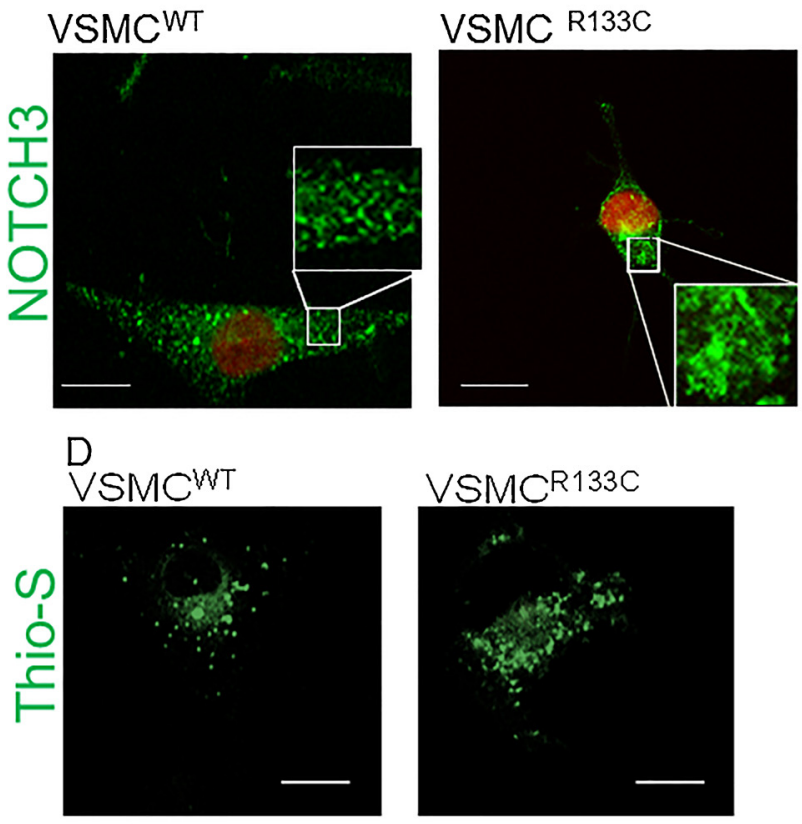

$\mathrm{E}$
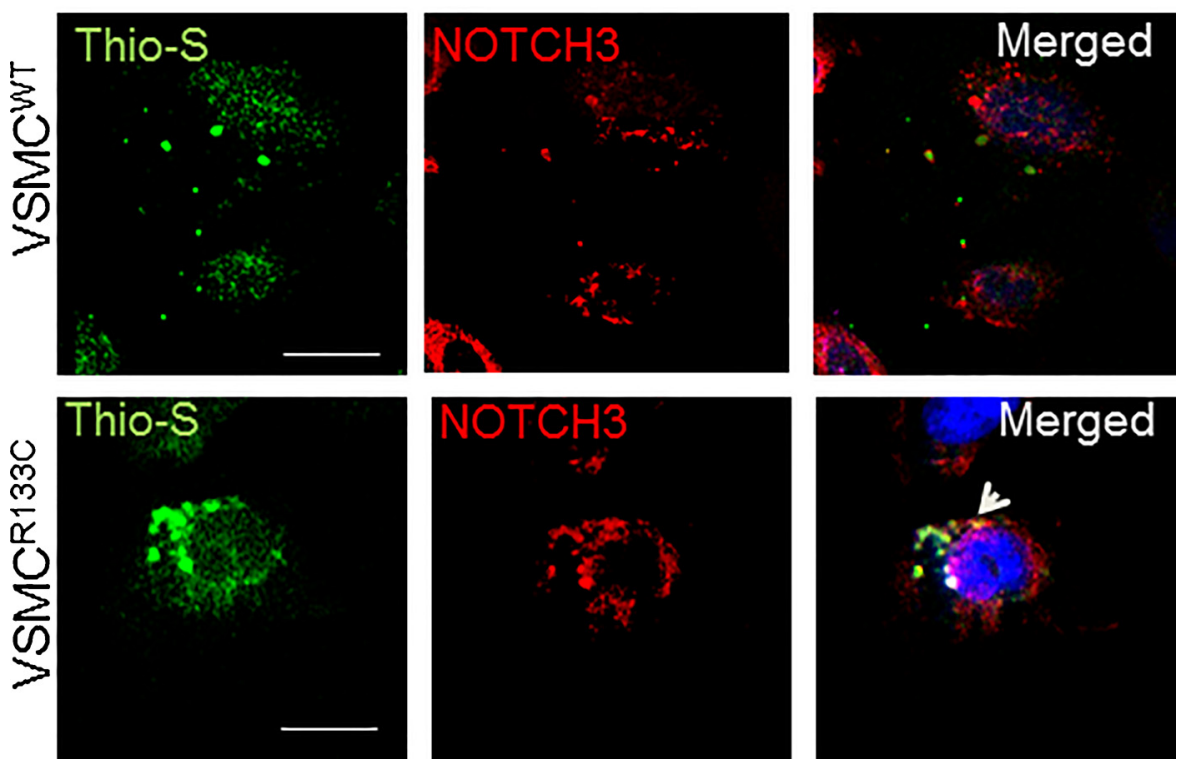

Fig. 1. Analysis of NOTCH3 accumulation in VSMC ${ }^{\mathrm{WT}}$ and VSMC ${ }^{\mathrm{R} 133 \mathrm{C}}$. (A) Quantitative RT-PCR analysis of NOTCH3 gene. The expression level of NOTCH3 gene is 2.6 fold higher in $\mathrm{VSMC}^{\mathrm{R} 133 \mathrm{C}}$ than in $\mathrm{VSMC}^{\mathrm{WT}}$. The data is from two independent experiments. The expression of NOTCH3 gene is normalized to the endogenous control gene, HPRT1, and the RQ (Relative Quantitation) is calculated using $\mathrm{VSMC}^{\mathrm{WT}}$ as a reference. (B) Western blot analysis demonstrates increased accumulation of NOTCH3 $(\sim 102 \mathrm{kDa})$ in $\mathrm{VSMC}^{\mathrm{R} 133 \mathrm{C}}$ compared to $\mathrm{VSMC}^{\mathrm{WT}}$. (C) VSMC ${ }^{\mathrm{WT}}$ and VSMC $^{\mathrm{R} 133 \mathrm{C}}$ are visualised by immunostaining using NOTCH3 antibody (green) followed by confocal microscopy analysis. Nuclei are stained with DAPI (visualized by red), scale bar $=5 \mu \mathrm{m}$. (D) Confocal microscopy of Thio-S positivity (green) shows more dense formation of large intracellular aggregates in VSMC $^{\text {R133C }}$ cells. Quantification revealed four times increased aggregate structures in $\mathrm{VSMC}^{\mathrm{R} 133 \mathrm{C}}$ compared to VSMC ${ }^{\mathrm{WT}}$ (right panel, graph) (paired $t$-test, ** $p<0.01$ ). Values shown are means \pm S.E.M. (E) Double staining shows co-localization of aggregated/ accumulated NOTCH3 (red) in Thio-S positive (green) aggregates. Thio-S: Thioflavin-S. (For interpretation of the references to colour in this figure legend, the reader is referred to the web version of this article.) chemiluminescent HRP substrate (Merck Millipore), the membranes were visualised. Autoradiography using Amersham Hyperfilm ECL (GE Healthcare) and digital imaging camera (FujiFilm LAS-3000 camera) was used for detection and the later for semi-quantitative analysis. The visualization of several WB analyses was also performed using Odyssey CLx Imaging system (Li-Cor) and ImageStudio software was used to visualize the blot. The secondary antibodies; anti-mouse Li-Cor IR Dye 800CW and anti-rabbit Li-Cor IR Dye 680CW were used.

\subsection{Statistical analysis}

Statistical comparison of values obtained for VSMC cell lines was performed by one-way ANOVA followed by Bonferroni's post-hoc test. Student $t$-test was used for two-group comparisons. p-values $<0.05$ were considered significant. The results are representative of three independent biological replicates expressed as mean \pm S.E.M. For lysosome quantification, approximately 20 VSMCs were counted for each sample using ImageJ (Abramoff et al., 2004). Western blot analysis was quantified by ImageJ software. 


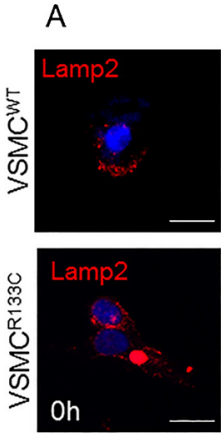

\section{CQ-treated}
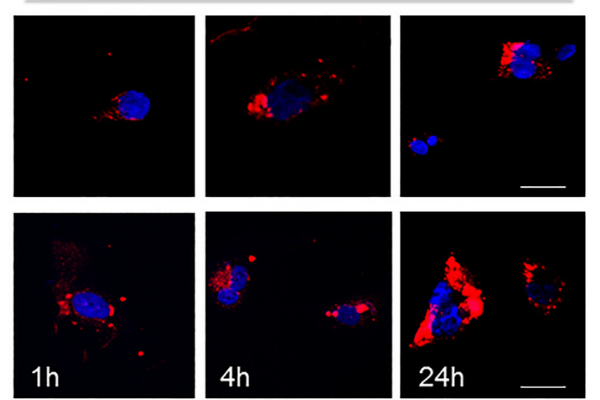

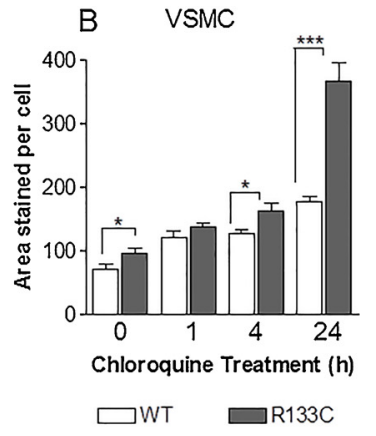

Fig. 2. Lysosomal vesicles in $\mathrm{VSMC}^{\mathrm{WT}}$ and $\mathrm{VSMC}^{\mathrm{R} 133 \mathrm{C}}$ after chloroquine (CQ) treatment. $\mathrm{VSMC}^{\mathrm{WT}}$ and $\mathrm{VSMC}^{\mathrm{R} 133 \mathrm{C}}$ are treated with CQ for 1,4 and $24 \mathrm{~h}$. The lysosomes are visualised by Lamp2 (red) and analysed by confocal microscopy. Nuclei are stained with DAPI (blue). Quantification of the lysosomes is performed manually by analysing 20 VSMCs for each sample. (A) Representative, confocal images show the lysosomes in $\mathrm{VSMC}^{\mathrm{WT}}$ and VSMC $^{\mathrm{R} 133 \mathrm{C}}$ before treatment and after CQ treatment for 1, 4, and $24 \mathrm{~h}$. (B) Lysosomal numbers are quantified at four different time points of CQ-treatment. At basal level, the number of lysosomes is lower in VSMC ${ }^{\mathrm{WT}}$ than VSMC $^{\mathrm{R} 133 \mathrm{C}}\left({ }^{*} p<0.05\right)$. The VSMC ${ }^{\mathrm{R} 133 \mathrm{C}}$ has a higher number of lysosomes compared to VSMC $^{\mathrm{WT}}$ after $24 \mathrm{~h}$ (paired $t$-test, $* * * p<$ 0.001 ). Values are shown as mean \pm S.E.M. Scale bar $=5 \mu \mathrm{m}$. (C) A representative WB analyses for detecting Lamp1 is shown (upper panel). Prior and after $1 \mathrm{~h}$ of CQ treatment, the level of Lamp1 protein is increased in VSMC $^{\mathrm{R} 133 \mathrm{C}}$. The Lamp1 expression is significantly increased after $24 \mathrm{~h}$ CQ-treatment (* $p<0.05$ ) (lower panel, graph). Experiments are conducted in triplicate. Anti-GAPDH was used as loading control. (For interpretation of the references to colour in this figure legend, the reader is referred to the web version of this article.)

Fig. 3. Accumulation of NOTCH3 in lysosomes of VSMCs. Representative confocal microscopy images of (A) $\mathrm{VSMC}^{\mathrm{WT}}$ and $\mathrm{VSMC}^{\mathrm{R} 133 \mathrm{C}}$ untreated and treated with CQ (B) are shown. The cells are stained with Lamp2 (red), NOTCH3 staining (green), and DAPI (cell nucleus; blue). An increased co-localization of NOTCH3 in lysosomes is observed in $\mathrm{VSMC}^{\mathrm{R} 133 \mathrm{C}}$ after $24 \mathrm{~h}$ CQ treatment (lower panel) compared to untreated VSMC $^{\mathrm{R} 133 \mathrm{C}}$. Scale bars $=10 \mu \mathrm{m}$. Experiments are conducted in triplicate. (C) Z Stack analysis by confocal microscopy confirmed the localization of NOTCH3 in lysosomes (lower panels). Scale bar $=10-20 \mu \mathrm{m}$. CQ: chloroquine. (For interpretation of the references to colour in this figure legend, the reader is referred to the web version of this article.)

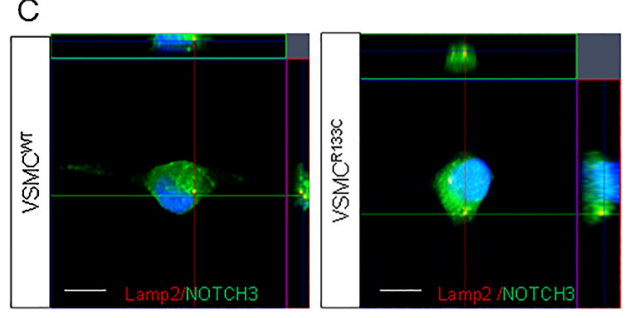

\section{Results}

\subsection{NOTCH3 accumulates in VSMC ${ }^{R 133 C}$}

To confirm expression of NOTCH3 in our cell line, qRT-PCR was utilized. We observed a 2.6 fold increased NOTCH3 expression in $\mathrm{VSMC}^{\mathrm{R} 133 \mathrm{C}}$ compared to the VSMC ${ }^{\mathrm{WT}}$ (Fig. 1A). This data was further confirmed on protein level by western blot (WB) on lysates from $\mathrm{VSMC}^{\mathrm{WT}}$ and VSMC ${ }^{\mathrm{R} 133 \mathrm{C}}$ cells (Fig. 1B). Both on mRNA and protein levels NOTCH3 is expressed more in VSMC ${ }^{\mathrm{R} 133 \mathrm{C}}$ compared to VSMC ${ }^{\mathrm{WT}}$. This is a phenotype we have observed previously (Panahi et al., 2018) and we suggested that the overexpression of NOTCH3 is due to compensatory mechanism of loss of function due to mutation.

To further investigate the expression and distribution of NOTCH3 in 
A

\section{VSMC}
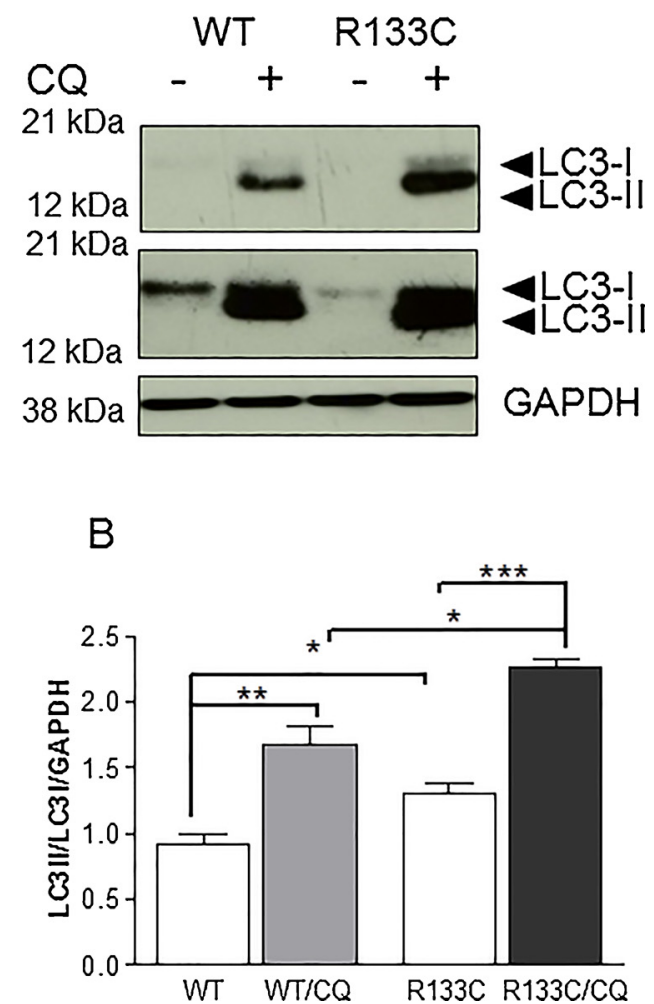

Fig. 4. Expression levels of LC3-I and LC3-II in VSMC ${ }^{\mathrm{WT}}$ and $\mathrm{VSMC}^{\mathrm{R} 133 \mathrm{C}}$. Western blot analysis of $\mathrm{VSMC}^{\mathrm{WT}}$ and $\mathrm{VSMC}^{\mathrm{R} 133 \mathrm{C}}$ in the absence or presence of CQ for $24 \mathrm{~h}$. (A) A representative WB analyses for detecting LC3 bands, LC3-I and LC3-II (upper panel; shorter exposure time). Prior to CQ-treatment, the amount of LC3-II is barely observed in cell lines (upper panel; shorter exposure time). While the blot exposed to a longer time revealed LC3-I and LC3-II bands (middle panel: blot exposed to longer time). $\mathrm{VSMC}^{\mathrm{WT}}$ and $\mathrm{VSMC}^{\mathrm{R} 133 \mathrm{C}}$ treated with CQ for $24 \mathrm{~h}$, show increased levels of LC3-II in both cell lines, which is higher in $\mathrm{VSMC}^{\mathrm{R} 133 \mathrm{C}}$. GAPDH; control for protein loading. (B) Quantitative analysis of LC3II/LC3I ratio from three independent WB analyses is shown. A significant difference between LC3-II/LC3-I levels before and after CQ-treatment (paired $t$ test, ${ }^{* * *} p<0.001$ ) is observed in VSMC ${ }^{\text {R133C }}$. Higher level of LC3-II/LC3-I ratio is also observed in $\mathrm{VSMC}^{\mathrm{R} 133 \mathrm{C}}$ compared to VSMC ${ }^{\mathrm{WT}}$ before and after treatment with CQ $(* p<0.05$, respectively). Values shown are means \pm S.E.M. CQ: chloroquine.

VSMCs, we performed confocal microscopy analysis. A dispersed dotlike staining of NOTCH3 in the cytoplasm of VSMC ${ }^{\mathrm{WT}}$ was seen (Fig. 1C, left), while the staining pattern of NOTCH3 in $\mathrm{VSMC}^{\mathrm{R} 133 \mathrm{C}}$ displayed large intense dots/aggregated forms in the cytoplasm (Fig. 1C, right and middle).

In order to assess intracellular protein aggregation, we performed Thio-S staining. Confocal microscopy observation of Thio-S positivity showed more dense formation of large intracellular aggregates in the cytoplasm of VSMC ${ }^{\mathrm{R} 133 \mathrm{C}}$ cells (Fig. 1D), suggesting that in these cells there are protein aggregations. We also observed a perinuclear accumulation of Thio-S-positive aggregated forms in VSMC ${ }^{\mathrm{R} 133 \mathrm{C}}$ cells (data not shown). Quantification revealed four times increased aggregate structures in VSMC ${ }^{\mathrm{R} 133 \mathrm{C}}$ compared to VSMC ${ }^{\mathrm{WT}}$ (Fig. 1D and graph). To examine whether cellular co-localization of aggregated NOTCH3 in VSMCs, we performed a co-staining using Thio-S and NOTCH3. The Thio-S-positive aggregates did not completely co-localize with NOTCH3 in $\mathrm{VSMC}^{\mathrm{WT}}$ cells, a phenotype that was much more pronounced in $\mathrm{VSMC}^{\mathrm{R} 133 \mathrm{C}}$ cells suggesting that NOTCH3 mutation causes an intracellular aggregation (Fig. 1E).

\subsection{Lysosomes vesicles and dilation after chloroquine (CQ) treatment in $V S M C^{W T}$ and $V S M C^{R 133 C}$}

We investigated the level of lysosome-associated membrane protein2 (Lamp2) by immunostaining prior to and after CQ, which has been attributed to an inhibitory effect (Mauthe et al., 2018) on lysosomal activity by decreasing autophagosome-lysosome fusion. The quantification of lysosomes was performed on confocal microscopy images. Prior to CQ-treatment $(0 \mathrm{~h})$, we observed that Lamp2-labelled vesicles in $\mathrm{VSMC}^{\mathrm{R} 133 \mathrm{C}}$ were larger than in VSMC ${ }^{\mathrm{WT}}$. After $1 \mathrm{~h}$ of exposure to 25 $\mu \mathrm{M} C Q$, both cell lines showed equal Lamp2-labelled vesicles in their cytoplasm. After $24 \mathrm{~h}$, lysosomes became greatly dilated in both cell lines, which were more evident in $\mathrm{VSMC}^{\mathrm{R} 133 \mathrm{C}}$ (Fig. 2A). Quantification of Lamp2 staining showed significantly increased prevalence in $\mathrm{VSMC}^{\mathrm{R} 133 \mathrm{C}}$ after CQ treatment compared to VSMC ${ }^{\mathrm{WT}}$ (Fig. 2B). Of note, $\mathrm{WB}$ analysis verified increased level of NOTCH3 in VSMC ${ }^{\mathrm{R} 133 \mathrm{C}}$ in comparison to VSMC ${ }^{\mathrm{WT}}$ prior to and after $24 \mathrm{~h}$ CQ-treatment (Fig. S1).

We analysed the protein levels of the Lamp1, another major lysosomal glycoprotein, by WB. After $1 \mathrm{~h}$ of CQ treatment, the level of Lamp1 protein was significantly increased in VSMC ${ }^{\mathrm{R} 133 \mathrm{C}}$ compared to VSMC $^{\text {WT }}$ (Fig. 2C). The Lamp1 expression was also increased after $24 \mathrm{~h}$ CQ-treatment (Fig. 2C). The quantification of WB analysis of Lamp1 revealed higher Lamp1 protein levels in $\mathrm{VSMC}^{\mathrm{R} 133 \mathrm{C}}$ after $24 \mathrm{~h}$ CQtreatment (Fig. 2C, lower panel, graph).

We also examined the levels of ubiquitinated proteins in these cells. We observed a moderate decrease in global ubiquitination pattern of in VSMC $^{\mathrm{R} 133 \mathrm{C}}$ by WB using mono- and poly-ubiquitin antibody (clone FK2) (Fig. S2), suggesting that NOTCH3-mutation in $\mathrm{VSMC}^{\mathrm{R} 133 \mathrm{C}}$ decreases the propensity to form cytoplasmic aggregates.

\subsection{Co-localization of NOTCH3 with lysosomes}

Previously, a study reported lysosomal-dependent degradation of NOTCH3 (Jia et al., 2009). To examine the possibility that degradation of aggregated NOTCH3 is related to lysosomal function in VSMC ${ }^{\mathrm{R} 133 \mathrm{C}}$, we performed immunostaining using anti-NOTCH3 and anti-Lamp2 antibodies followed by confocal microscopy.

Our results showed NOTCH3 co-localization with lysosomes prior to (Fig. 3A), and after $24 \mathrm{~h}$ CQ-treatment in both cell lines (Fig. 3B). The co-localization of NOTCH3 with lysosomes was more evident in VSMC $^{\mathrm{R} 133 \mathrm{C}}$ (Fig. 3B, C), which might be a result of autophagy dysregulation or a deficiency of autophagosomes-lysosomes fusion process (Terman et al., 2007).

\subsection{Higher amount of autophagosomes in VSMC ${ }^{133 C}$ after CQ-treatment}

To examine the involvement of the autophagy pathway, we performed WB to detect the protein level of endogenous LC3, a well-established autophagosome marker (Klionsky et al., 2012). VSMC ${ }^{\mathrm{WT}}$ and VSMC $^{\mathrm{R} 133 \mathrm{C}}$ were treated for $24 \mathrm{~h}$ with CQ. Endogenous LC3 is detected as two bands following SDS-PAGE and immunoblotting: the LC3-I represents the cytosolic form, while LC3-II is present on the membranes of autophagy vesicles.

Fig. 4A shows a representative WB analysis detecting two LC3 bands, LC3-I and LC3-II (Fig. 4A, upper (low exposed) and middle panel (high exposed). Prior to CQ-treatment, the amount of LC3-II was barely observed in cell lines (Fig. 4A). Hence, treatment with CQ for $24 \mathrm{~h}$ induced an increase in the level of LC3-II in the VSMC ${ }^{\mathrm{WT}}$ and VSMC ${ }^{\mathrm{R} 133 \mathrm{C}}$. However, the increased level of LC3-II was more obvious in VSMC ${ }^{\mathrm{R} 133 \mathrm{C}}$ than in the VSMC ${ }^{\mathrm{WT}}$ (Fig. 4A), indicating a higher number of autophagosomes in CADASIL. Since cytosolic LC3 ratio has been suggested for a quantitative index of autophagy, the ratio of LC3-II/LC3-I was examined and quantified. In the presence of CQ, the LC3-II/LC3-I ratio was greater in the VSMC ${ }^{\mathrm{R} 133 \mathrm{C}}$ compared to the $\mathrm{VSMC}^{\mathrm{WT}}$ (Fig. 4B), suggesting that R133C mutation in VSMC cause a dysregulation in autophagy pathway. 

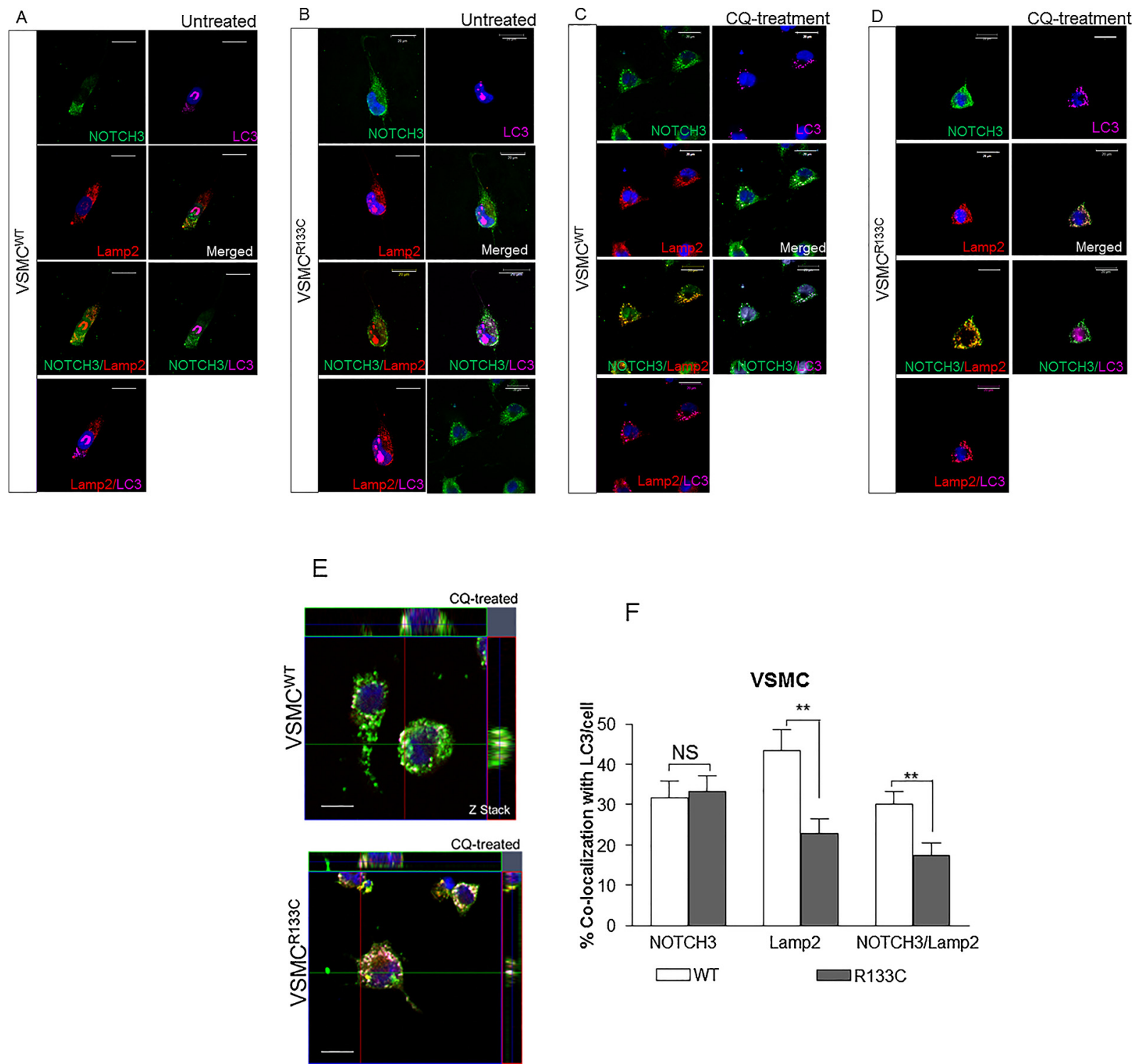

Fig. 5. NOTCH3 co-localization with LC3 and Lamp2 in VSMC ${ }^{\mathrm{WT}}$ and VSMC ${ }^{\mathrm{R} 133 \mathrm{C}}$. Representative images of confocal microscopy analysis of VSMC ${ }^{\mathrm{WT}}$ and VSMC ${ }^{\mathrm{R} 133 \mathrm{C}}$ in untreated (A, B) and after exposure to $24 \mathrm{~h}$ exposure to CQ (C; D) are shown. Triple immunofluorescence staining on VSMCs against NOTCH3 (green), LC3 (purple), and Lamp2 (red) in VSMC ${ }^{\mathrm{WT}}$ and VSMC ${ }^{\mathrm{R} 133 \mathrm{C}}$ is shown (A-D). Nuclei are stained with DAPI (blue). Scale bar $=10-20 \mu \mathrm{m}$. (E) Z-stack analysis presenting and confirming the accumulation and co-localization of NOTCH3 in LC3 and Lamp2. Scale bars $=10-20 \mu \mathrm{m}$. (F) Co-localization of LC3 with Lamp2 (double staining) and combination of NOTCH3 and Lamp2 (triple staining) is significantly decreased in VSMC ${ }^{\mathrm{R} 133 \mathrm{C}}$ in comparison to VSMC ${ }^{\mathrm{WT}}$ (paired $t$-test, ** $p<0.01$, respectively). $\mathrm{VSMC}^{\mathrm{WT}}$ showed relative similar LC3 co-localization with NOTCH3 compared to VSMC ${ }^{\mathrm{R} 133 \mathrm{C}}$. Values shown are means \pm S.E.M. NS $=$ not significant. CQ: chloroquine. (For interpretation of the references to colour in this figure legend, the reader is referred to the web version of this article.)

\subsection{Low amount of NOTCH3 in autophagosome vesicles in VSMC ${ }^{R 133 C}$}

Next, we examined if the autophagy-lysosomal pathway is involved in the degradation of accumulated NOTCH3 in CADASIL. LC3 is the only known mammalian protein identified that stably associates with the autophagosome membranes. In order to investigate the fusion of autophagosomes with and to examine whether aggregated/accumulated NOTCH3 is co-localizing with the lysosomal marker, we performed immunostaining with anti-LC3, -Lamp2, and -NOTCH3 antibodies in the absence or presence of CQ, and analysed by confocal microscopy.

Prior to CQ-treatment, the prevalence of NOTCH3 in LC3-positive puncta in VSMC ${ }^{\mathrm{WT}}$ was relatively less compared to VSMC ${ }^{\mathrm{R} 133 \mathrm{C}}$ (Fig. 5A, B). After CQ-treatment, in agreement with the WB results, a marked increase of LC3-positive puncta in the cytoplasm of the VSMC ${ }^{\mathrm{R} 133 \mathrm{C}}$ was detected as compared to VSMC ${ }^{\mathrm{WT}}$ (Fig. 5B). An increase of LC3-positive puncta and Lamp2 were observed in both VSMC ${ }^{\mathrm{WT}}$ and VSMC ${ }^{\mathrm{R} 133 \mathrm{C}}$ after treatment. Of note, a more intense puncta staining (both LC3 and Lamp2) was visible in VSMC ${ }^{\mathrm{R} 133 \mathrm{C}}$ (Fig. 5C, D). Z-stacks analysis confirmed the co-localization of NOTCH3 in LC3-Lamp2 positive puncta (Fig. 5E).

Quantification of the percentage of LC3-positive puncta co-localized with NOTCH3 and Lamp2 was performed on VSMCs treated with CQ for $24 \mathrm{~h}$ (Fig. 5F). VSMC ${ }^{\text {WT }}$ showed relative similar LC3 co-localization with NOTCH3 compared to $\mathrm{VSMC}^{\mathrm{R} 133 \mathrm{C}}(31.7 \pm 4.1 \%$ and $33.3 \pm 3.8 \%$ respectively), however the co-localization of LC3 with Lamp2 (LC3 + Lamp2, double staining) and combination of NOTCH3 and Lamp2 (LC3 + Lamp2 + NOTCH3, triple staining) was significantly decreased in $\mathrm{VSMC}^{\mathrm{R} 133 \mathrm{C}}$ in comparison to VSMC ${ }^{\mathrm{WT}}$ (Fig. 5F). These data suggest an impairment of the autophagosome-lysosome fusion in $\mathrm{VSMC}^{\mathrm{R} 133 \mathrm{C}}$ compared to $\mathrm{VSMC}^{\mathrm{WT}}$. 

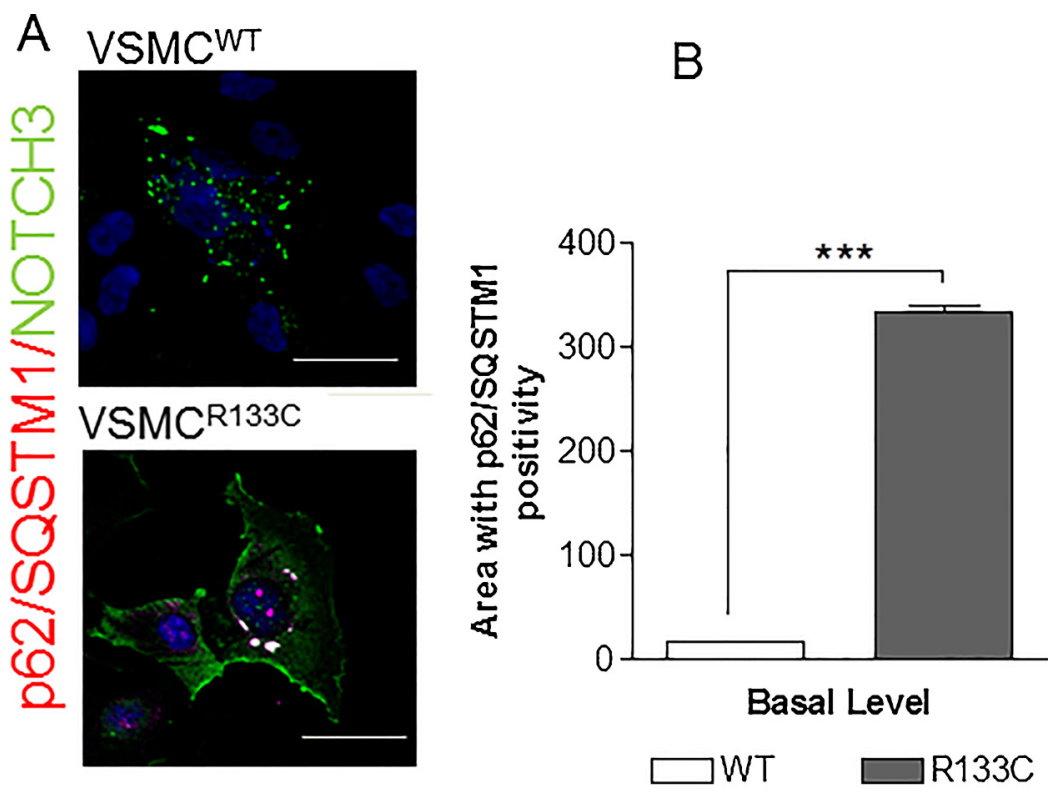

Fig. 6. Level of p62/SQSTM1 in VSMC ${ }^{\mathrm{WT}}$ and $\mathrm{VSMC}^{\mathrm{R} 133 \mathrm{C}}$. (A) Confocal microscopy images representing the expression level of p62/SQSTM1 in VSMCs. Double immunostaining of p62/SQSTM1 (purple/red) and NOTCH3 (green) is shown. (B) Quantification by ImageJ analysis showed an increased p62/SQSTM1 level at the basal level (*** $p<0.001$ ). (C) A representative of WB is shown. VSMCs are cultured in the absence and presence of CQ for $24 \mathrm{~h}$. The p62/SQSTM1 expression levels are analysed by WB $(n=3)$. GAPDH has been used as a loading control and the relative intensity of p62/SQSTM1 level is normalized to GAPDH. Quantification of three independent WB analysis demonstrated higher level of p62/SQSTM1 in VSMC ${ }^{\mathrm{R} 133 \mathrm{C}}$ than in VSMC ${ }^{\mathrm{WT}}$ prior to $(* p<0.05)$ CQ treatment. The level of p62/SQSTM1 is significantly higher in $\mathrm{VSMC}^{\mathrm{R} 133 \mathrm{C}}$ after treatment with CQ compared to untreated VSMC ${ }^{\mathrm{R} 133 \mathrm{C}}(* * * p<0.001)$ (lower panel). $* * p<$ 0.01 , Values shown are means \pm S.E.M. CQ: chloroquine. (For interpretation of the references to colour in this figure legend, the reader is referred to the web version of this article.)
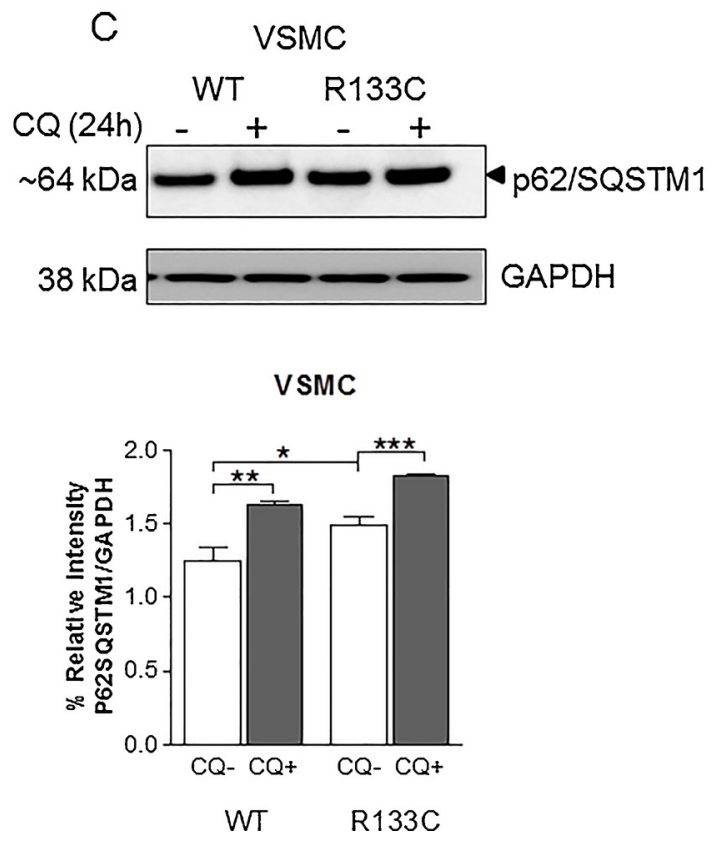

\subsection{Degradation of p62/SQSTM1 by autophagy activity in VSMC ${ }^{R 133 C}$}

The polyubiquitin-binding protein p62/SQSTM1 is necessary to target protein aggregates for degradation via autophagy (Bjorkoy et al., 2006), and/or the ubiquitin-proteasome system (Babu et al., 2005; Bardag-Gorce et al., 2005; Seibenhener et al., 2004). To investigate whether the protein clearance was defective in CADASIL cell line, we analysed the p62/SQSTM1 protein by immunostaining and WB with and without CQ.

Confocal microscopy analysis revealed higher levels of p62/ SQSTM1 in VSMC ${ }^{\mathrm{R} 133 \mathrm{C}}$ as compared to VSMC ${ }^{\mathrm{WT}}$ before any treatment (Fig. 6A, B).

WB analysis showed that the p62/SQSTM1 levels were significantly lower in VSMC ${ }^{\mathrm{WT}}$ than in VSMC ${ }^{\mathrm{R} 133 \mathrm{C}}$ prior to CQ-treatment (Fig. 6C, graph). Once treated, higher level of p62/SQSTM1 was observed in both cell lines. Thus the level of increased p62/SQSTM1 was significantly higher in $\mathrm{VSMC}^{\mathrm{R} 133 \mathrm{C}}$ than in VSMC ${ }^{\mathrm{WT}}$ (Fig. 6C, graph).
3.7. VSMC ${ }^{R 133 C}$ exhibit phosphorylation of proteins in the ERK/MAPK
signalling pathway

The ERK/MAPK signalling pathway has been linked to the regulation of autophagy (Zhou et al., 2015), and thus could possibly underlie the observed aberrations. Therefore, the levels of four proteins involved in the ERK/MAPK signalling pathway; extracellular-signal-regulated kinase (ERK), S6 ribosomal protein (S6RP), P70 S6 kinase (P70 S6K), and mammalian target of rapamycin (mTOR), and their phosphorylated forms were investigated by WB analyses.

Analysis showed equal levels of ERK, S6 RP, and P70 S6K in $\mathrm{VSMC}^{\mathrm{WT}}$ and VSMC ${ }^{\mathrm{R} 133 \mathrm{C}}$ (Fig. 7). In contrast, the phosphorylated forms of these proteins were expressed at higher levels in the VSMC ${ }^{\mathrm{R} 133 \mathrm{C}}$ (Fig. 7). mTOR level was significantly higher in $\mathrm{VSMC}^{\mathrm{R} 133 \mathrm{C}}$ whereas (Fig. 7) its phosphorylated counterpart were not detected in the WB in either cell line (data not shown). 

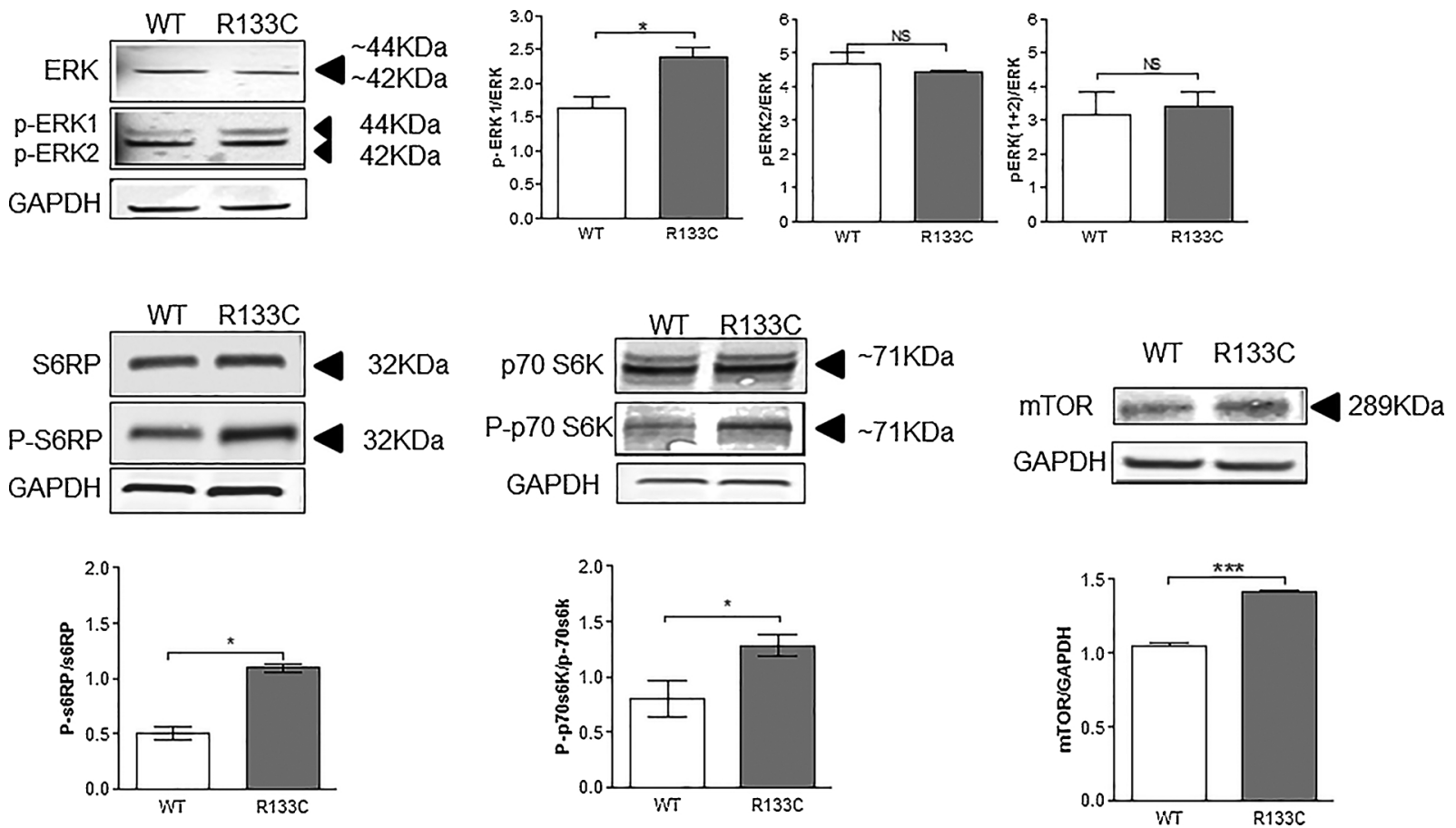

Fig. 7. Levels of proteins involved in ERK/MAPK signalling pathway. (A) The VSMC ${ }^{\mathrm{WT}}$ and VSMC ${ }^{\mathrm{R} 133 \mathrm{C}}$ were lysed and the level of ERK, S6RP, P70 S6K, and mammalian target of rapamycin (mTOR), and their phosphorylated forms are investigated by WB analyses. The percentage of relative intensity of the bands is normalized to loading control, GAPDH. Quantification of phosphorylated (p)-ERK1/total ERK showed a significant increase in VSMC ${ }^{\mathrm{R} 133 \mathrm{C}}\left({ }^{*} p<0.05\right)$. The

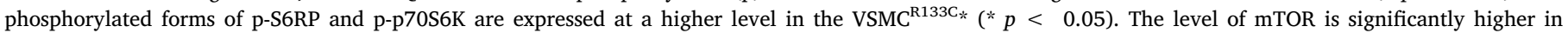
VSMC $^{\mathrm{R} 133 \mathrm{C}}$ compared to VSMC ${ }^{\mathrm{WT}}\left({ }^{*} p<0.001\right)$. Values shown are means \pm S.E.M. The intensity of all bands is normalized to GAPDH.

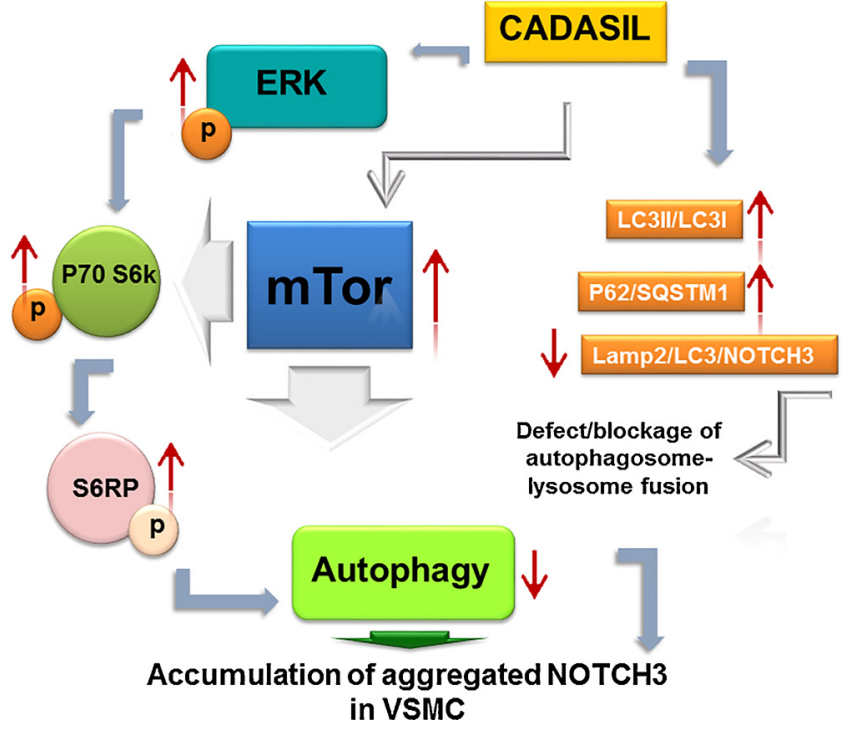

Fig. 8. Hypothetical connection of ERK/MAPK signalling pathway and autophagy signalling in CADASIL. Schematic summary of the signalling pathway and the results is shown. The kinase mTOR is a critical regulator of autophagy induction, with activated mTOR (Akt and ERK/MAPK signalling) suppressing autophagy, and negative regulation of mTOR (AMPK and p53 signalling) promoting it. However, the activation of the ERK/MAPK pathway can be upregulated via diverse biological processes in cells, e.g. inflammation. The phosphorylation of ERK1/2 activates p70S6k and S6RP and cause phosphorylation of these proteins, which in turn might activate/modify autophagy processing. However, increased p-ERK/MAPK level might inhibit the regulatory effect of mTOR involved in autophagy. Regardless of that observed increase level of LC3II/LC3I ratio, P62/SQSTM1 accumulation and lower co-localization of NOTCH3 in Lamp2/LC3 + cells in VSMC ${ }^{\mathrm{R} 133 \mathrm{C}}$, indicates a deficiency of the fusion steps in autophagic-lysosomal pathway in CADASIL.

\section{Discussion}

In CADASIL, one of the major pathological hallmarks is loss of VSMCs and successful autophagy can promote VSMC survival (Gray et al., 2007). VSMC cells carrying a mutation in the NOTCH3 gene (e.g. $\mathrm{R} 133 \mathrm{C}$ ) may be subject to a higher level of intracellular stimuli and/or insults compared to non-mutated NOTCH3. The VSMC carrying CADASIL mutation is notoriously susceptible to stress; therefore, we questioned whether the autophagy machinery might be dysregulated as a consequence of misfolded mutated NOTCH3.

Here, we report increased expression and accumulation of NOTCH3 in VSMC ${ }^{\mathrm{R} 133 \mathrm{C}}$ which was partially co-stained with Thio-S positivity in VSMC $^{\mathrm{R} 133 \mathrm{C}}$ indicating NOTCH3 as an aggregated protein in the disease condition. Furthermore, our results showed reduced localization of mutated NOTCH3 in the autophagosome-lysosome fusion steps, suggesting that autophagy, is not completely functioning in CADASIL cells.

We found increased immunoreactivity of Lamp2, lysosomal marker, prior to and after CQ-treatment in VSMC ${ }^{\mathrm{R} 133 \mathrm{C}}$. This data was in line with a previous study showing increased large lysosomes and lysosomal inclusions in pericytes in the frontal cortex of transgenic mice expressing Notch $3^{\mathrm{R} 90 \mathrm{C}}$ (Gu et al., 2012). Furthermore, using LC3, a well-established autophagosome marker (Klionsky et al., 2012), we investigated whether the autophagy system is dysregulated in $\mathrm{VSMC}^{\mathrm{R} 133 \mathrm{C}}$ cells. Accumulation of LC3 may suggest either the autophagy upregulation or a blockage of autophagosome-lysosomal pathway (Rubinsztein et al., 2009). We observed induced LC3-II/LC3I ratio in VSMC ${ }^{\mathrm{R} 133 \mathrm{C}}$ cells suggesting impaired autophagosome degradation prior to and after CQ insult; a compound which inhibits lysosome protein degradation (Wibo and Poole, 1974; Geng et al., 2010).

The autophagic cargo receptor, p62/SQSTM1, is necessary to target proteins for degradation via autophagy (Pankiv et al., 2007) and accumulation of p62/SQSTM1 could result from defective autophagy clearance. Prior to and after CQ-treatment, we observed an increase of p62/SQSTM1 level in VSMC ${ }^{\mathrm{R} 133 \mathrm{C}}$ by confocal microscopy and WB. 


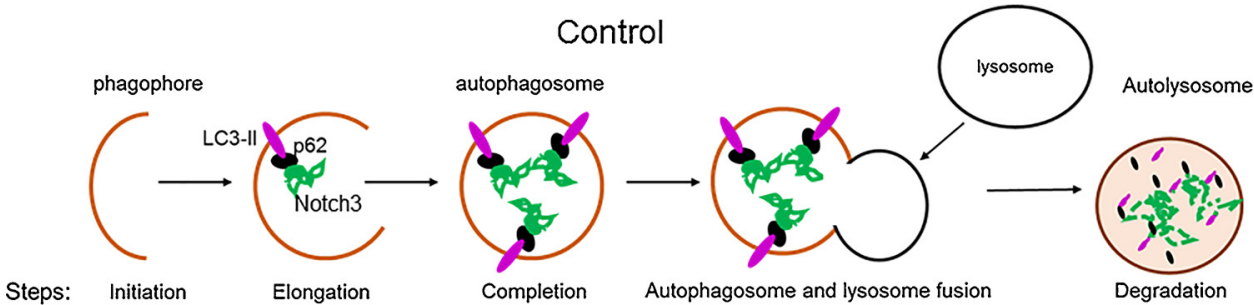

Steps: Initiation
Completion
Autophagosome and lysosome fusion
Fig. 9. Proposed model of defected autophagylysosomal pathway in CADASIL. Five steps in autophagy that leads to degradation. Initiation begins with the isolation of membrane needed to form the phagophore. This gets further elongated, during which proteins/particles are recruited, one manner being through p62/ SQSTM1, which binds to LC3-II, a protein that binds to the membrane of the autophagosome. After elongation and completion of the phagophore into an autophagosome, lysosome fusion occurs allowing for the degradation of the contents of the autophagosome. This occurs in normal cellular condition of control VSMCs. However, a defect of NOTCH3 recognition by autophagy pathway and lysosome fusion with autophagosome occurs in CADASIL leading to decreased degradation of the autophagosome content, namely NOTCH3.

Steps: Initiation

Elongation
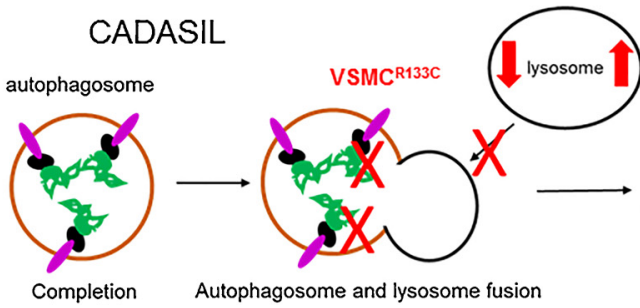

Autolysosome

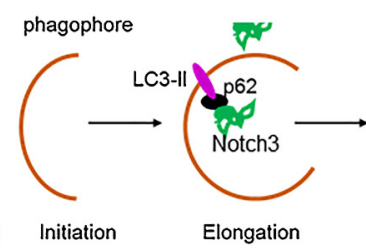

Thus, it is tempting to speculate that the increased accumulation of aggregated NOTCH3 in p62/SQSTM1-positive structures could be caused by suppression of autophagy clearance. However, the expression level of p62/SQSTM1 can also be changed independently of autophagy (Bardag-Gorce et al., 2005; Kuusisto et al., 2001; Nakaso et al., 2004). Further, the co-localization of LC3 with Lamp2 (double staining) and combination of NOTCH3 and Lamp2 (triple staining) was significantly decreased in $\mathrm{VSMC}^{\mathrm{R} 133 \mathrm{C}}$ in comparison to $\mathrm{VSMC}^{\mathrm{WT}}$ suggesting an impairment of the autophagosome-lysosome fusion in VSMC ${ }^{\mathrm{R} 133 \mathrm{C}}$. Hence, we suggest that either autophagy dysregulation or a deficiency of autophagosomes-lysosomes fusion take place in CADASIL (Terman et al., 2007).

It has been proposed that the degeneration of the smooth muscle layer in arteries/arterioles of CADASIL patients is the result of increased VSMC death (Gray et al., 2007; Viitanen et al., 2013). Among the reasons behind VSMC degeneration, dysfunctional autophagy is a possible factor. The autophagy dysfunction or an insufficient autophagy in stress conditions has been suggested to be the cause of apoptosis in CADASIL astrocytes (Hase et al., 2018). Further, the insufficient autophagy has been linked to lower proliferation rate of VSMCs (Panahi et al., 2018) (here $\mathrm{VSMC}^{\mathrm{R} 133 \mathrm{C}}$ ), and VSMC secreted matrix proteins suggesting a linkage of autophagy level in the development of vascular aging (Tai et al., 2016). We have previously demonstrated that the reduced number of VSMC cells is rather due to impaired VSMC proliferation (Viitanen et al., 2013) showing an important role of TGF $\beta$ in the proliferation process (Panahi et al., 2018). Further, the mutant NOTCH3 was shown to be more prone to form aggregates than NOTCH $3^{W T}$ (Takahashi et al., 2010), and that the mutant aggregates were resistant to degradation, ultimately impairing cell proliferation. In addition, an altered cytoskeleton structure of VSMC ${ }^{\mathrm{R} 13 \mathrm{C}}$ could hamper the autophagy-lysosomal function through its negative affect on actin organization (Tikka et al., 2012), causing a defect/delay in autophagosome-lysosome fusion, as well as the co-localization of NOTCH3 in the organelles involved in this process. As we presented here, the accumulation of intracellular mutated-NOTCH3 could be a consequence of low efficacy of autophagy pathway involved in aggregated NOTCH3 in CADASIL. However, the mechanisms leading to autophagy dysfunction as well as those linking defective autophagy in CADASIL require further investigation.

Another possible manner by which mutated NOTCH3 could affect autophagy is through ERK/MAPK pathway (Zhou et al., 2015), which is activated by NOTCH3 through undefined crosstalk (Wang et al., 2002). This could be a way in which NOTCH3 mutations lead to a dysregulation in autophagy, either through the constant activation of ERK/ MAPK, or the prevention of the crosstalk necessary for activation and

thus it is a possible cause of these aberrations. WBs indicated hyperphosphorylation of three proteins involved in ERK/MAPK signalling pathway: p-ERK, p-P70 S6K and p-S6 RP. ERK hyper-phosphorylation disrupts gene expression, and S6 RP is thought to regulate translation and its hyper-phosphorylation will similarly disrupt gene expression. The ERK/MAPK pathway also includes mTOR (Wang et al., 2009), which acts via S6K (Magnuson et al., 2012), providing another way by which the ERK/MAPK pathway may influence autophagy (Fig. 8). Quantification of mTOR level was higher in VSMC ${ }^{\mathrm{R} 133 \mathrm{C}}$ as compared to its counterpart and ERK1/2/MAPK activation leads to the inhibition of mTOR, a negative regulator of autophagy (Wang et al., 2009). All these data may suggest a dysfunction of the autophagy flux, e.g. the impairment of the autophagosome-lysosome fusion, with consequent accumulation of autophagosomes, lysosomes and their cargo. Hence, we did not detect phosphorylated mTOR in either cell lines as analysed by WB (data not shown). As the ERK/MAPK pathway contributes to myriad aspects of cellular physiology, its activation in CADASIL VSMCs may implicate other processes in CADASIL pathogenesis, such as insulin resistance and inflammation. In addition, the mechanism by which NOTCH3 influences cellular signalling in CADASIL may hold broader implications for the cellular processes behind more common diseases like diabetes.

For this study, we acknowledge some limitations. The in vitro data was based on low numbers of cerebral VSMCs from CADASIL and control cell lines. Despite that, we were able to demonstrate a possible dysfunction of autophagosome-lysosomal pathway in CADASIL. However, we should emphasize the difficulties and limitations of preparing cerebral VSMCs derived from CADASIL patients. Furthermore, supplementary experiments of genes involved in autophagy pathway are needed.

Taken together, in this study we suggest that the clearance of NOTCH3 by the autophagosome-lysosome pathway is compromised in VSMC $^{\mathrm{R} 133 \mathrm{C}}$ (Fig. 9). How this process occurs, and what role it plays in the molecular mechanism of CADASIL remains elusive.

\section{Conflict of interest statement}

The authors have no actual or potential conflict of interest to disclose.

\section{Acknowledgements}

This work was supported by the Swedish Research Council, Gun and Bertil Stohne's Foundation, Olle Engkvist Byggmästare Foundation, Foundation for Old Servants, Dementia Association, and Karolinska 
Institutet Foundations. The authors would like to thank Dr. Pavel P. Pavlov for the critical reading of this manuscript.

\section{Appendix A. Supplementary data}

Supplementary material related to this article can be found, in the online version, at doi:https://doi.org/10.1016/j.ejcb.2018.10.001.

\section{References}

Abramoff, M.D., Magalhães, Paulo J., Ram, Sunanda J., 2004. Image processing with ImageJ. Biophoton. Int. 11, 36-42.

Andersson, E.R., Sandberg, R., Lendahl, U., 2011. Notch signaling: simplicity in design, versatility in function. Development 138, 3593-3612.

Arboleda-Velasquez, J.F., Manent, J., Lee, J.H., Tikka, S., Ospina, C., Vanderburg, C.R., Frosch, M.P., Rodriguez-Falcon, M., Villen, J., Gygi, S., Lopera, F., Kalimo, H., Moskowitz, M.A., Ayata, C., Louvi, A., Artavanis-Tsakonas, S., 2011. Hypomorphic Notch 3 alleles link Notch signaling to ischemic cerebral small-vessel disease. Proc Natl. Acad. Sci. U. S. A. 108, E128-135.

Artavanis-Tsakonas, S., Rand, M.D., Lake, R.J., 1999. Notch signaling: cell fate control and signal integration in development. Science 284, 770-776.

Babu, J.R., Geetha, T., Wooten, M.W., 2005. Sequestosome 1/p62 shuttles polyubiquitinated tau for proteasomal degradation. J. Neurochem. 94, 192-203.

Bardag-Gorce, F., Francis, T., Nan, L., Li, J., He Lue, Y., French, B.A., French, S.W., 2005 Modifications in P62 occur due to proteasome inhibition in alcoholic liver disease. Life Sci. 77, 2594-2602.

Bjorkoy, G., Lamark, T., Johansen, T., 2006. p62/SQSTM1: a missing link between protein aggregates and the autophagy machinery. Autophagy 2, 138-139.

Borggrefe, T., Oswald, F., 2009. The Notch signaling pathway: transcriptional regulation at Notch target genes. Cell. Mol. Life Sci. 66, 1631-1646.

Ciechanover, A., 2005. Proteolysis: from the lysosome to ubiquitin and the proteasome. Nat. Rev. Mol. Cell. Biol. 6, 79-87.

Ciechanover, A., Kwon, Y.T., 2015. Degradation of misfolded proteins in neurodegenerative diseases: therapeutic targets and strategies. Exp. Mol. Med. 47, e147.

Dichgans, M., Mayer, M., Uttner, I., Bruning, R., Muller-Hocker, J., Rungger, G., Ebke, M., Klockgether, T., Gasser, T., 1998. The phenotypic spectrum of CADASIL: clinical findings in 102 cases. Ann. Neurol. 44, 731-739.

Geng, Y., Kohli, L., Klocke, B.J., Roth, K.A., 2010. Chloroquine-induced autophagic vacuole accumulation and cell death in glioma cells is p53 independent. NeuroOncology 12, 473-481.

Gimbrone Jr., M.A., Cotran, R.S., Folkman, J., 1974. Human vascular endothelial cells in culture. Growth and DNA synthesis. J. Cell Biol. 60, 673-684.

Gray, F., Polivka, M., Viswanathan, A., Baudrimont, M., Bousser, M.G., Chabriat, H., 2007. Apoptosis in cerebral autosomal-dominant arteriopathy with subcortical infarcts and leukoencephalopathy. J. Neuropathol. Exp. Neurol. 66, 597-607.

Gu, X., Liu, X.Y., Fagan, A., Gonzalez-Toledo, M.E., Zhao, L.R., 2012. Ultrastructural changes in cerebral capillary pericytes in aged Notch 3 mutant transgenic mice. Ultrastruct. Pathol. 36, 48-55.

Hase, Y., Chen, A., Bates, L.L., Craggs, L.J., Yamamoto, Y., Gemmell, E., Oakley, A.E., Korolchuk, V.I., Kalaria, R.N., 2018. Severe white matter astrocytopathy in CADASIL. Brain Pathol. https://doi.org/10.1111/bpa.12621. Accepted Author Manuscript.

Ihalainen, S., Soliymani, R., Iivanainen, E., Mykkanen, K., Sainio, A., Poyhonen, M., Elenius, K., Jarvelainen, H., Viitanen, M., Kalimo, H., Baumann, M., 2007. Proteome analysis of cultivated vascular smooth muscle cells from a CADASIL patient. Mol. Med. 13, 305-314.

Ishiko, A., Shimizu, A., Nagata, E., Takahashi, K., Tabira, T., Suzuki, N., 2006. Notch3 ectodomain is a major component of granular osmiophilic material (GOM) in CADASIL. Acta Neuropathol. 112, 333-339.

Jia, L., Yu, G., Zhang, Y., Wang, M.M., 2009. Lysosome-dependent degradation of Notch3. Int. J. Biochem. Cell Biol. 41, 2594-2598.

Joutel, A., Corpechot, C., Ducros, A., Vahedi, K., Chabriat, H., Mouton, P., Alamowitch, S., Domenga, V., Cecillion, M., Marechal, E., Maciazek, J., Vayssiere, C., Cruaud, C., Cabanis, E.A., Ruchoux, M.M., Weissenbach, J., Bach, J.F., Bousser, M.G., TournierLasserve, E., 1996. Notch3 mutations in CADASIL, a hereditary adult-onset condition causing stroke and dementia. Nature 383, 707-710.

Joutel, A., Vahedi, K., Corpechot, C., Troesch, A., Chabriat, H., Vayssiere, C., Cruaud, C., Maciazek, J., Weissenbach, J., Bousser, M.G., Bach, J.F., Tournier-Lasserve, E., 1997. Strong clustering and stereotyped nature of Notch3 mutations in CADASIL patients. Lancet 350, 1511-1515.

Joutel, A., Andreux, F., Gaulis, S., Domenga, V., Cecillon, M., Battail, N., Piga, N., Chapon, F., Godfrain, C., Tournier-Lasserve, E., 2000. The ectodomain of the Notch3 receptor accumulates within the cerebrovasculature of CADASIL patients. J. Clin. Invest. 105, 597-605.

Karlstrom, H., Beatus, P., Dannaeus, K., Chapman, G., Lendahl, U., Lundkvist, J., 2002. A CADASIL-mutated Notch 3 receptor exhibits impaired intracellular trafficking and maturation but normal ligand-induced signaling. Proc. Natl. Acad. Sci. U. S. A. 99,
17119-17124.

Klionsky, D.J., Abdalla, F.C., Abeliovich, H., Abraham, R.T., Acevedo-Arozena, A., et al., 2012. Guidelines for the use and interpretation of assays for monitoring autophagy. Autophagy 8, 445-544.

Kuusisto, E., Suuronen, T., Salminen, A., 2001. Ubiquitin-binding protein p62 expression is induced during apoptosis and proteasomal inhibition in neuronal cells. Biochem. Biophys. Res. Commun. 280, 223-228.

Magnuson, B., Ekim, B., Fingar, D.C., 2012. Regulation and function of ribosomal protein S6 kinase (S6K) within mTOR signalling networks. Biochem. J. 441, 1-21.

Martini-Stoica, H., Xu, Y., Ballabio, A., Zheng, H., 2016. The autophagy-lysosomal pathway in neurodegeneration: a TFEB perspective. Trends Neurosci. 39, 221-234.

Mauthe, M., Orhon, I., Rocchi, C., Zhou, X., Luhr, M., Hijlkema, K.J., Coppes, R.P., Engedal, N., Mari, M., Reggiori, F., 2018. Chloroquine inhibits autophagic flux by decreasing autophagosome-lysosome fusion. Autophagy 14, 1435-1455.

Miao, Q., Paloneva, T., Tuominen, S., Poyhonen, M., Tuisku, S., Viitanen, M., Kalimo, H., 2004. Fibrosis and stenosis of the long penetrating cerebral arteries: the cause of the white matter pathology in cerebral autosomal dominant arteriopathy with subcortical infarcts and leukoencephalopathy. Brain Pathol. 14, 358-364.

Nakaso, K., Yoshimoto, Y., Nakano, T., Takeshima, T., Fukuhara, Y., Yasui, K., Araga, S., Yanagawa, T., Ishii, T., Nakashima, K., 2004. Transcriptional activation of p62/ A170/ZIP during the formation of the aggregates: possible mechanisms and the role in Lewy body formation in Parkinson's disease. Brain Res. 1012, 42-51.

Opherk, C., Duering, M., Peters, N., Karpinska, A., Rosner, S., Schneider, E., Bader, B., Giese, A., Dichgans, M., 2009. CADASIL mutations enhance spontaneous multimerization of NOTCH3. Hum. Mol. Genet. 18, 2761-2767.

Panahi, M., Yousefi Mesri, N., Samuelsson, E.B., Coupland, K.G., Forsell, C., Graff, C., Tikka, S., Winblad, B., Viitanen, M., Karlstrom, H., Sundstrom, E., Behbahani, H., 2018. Differences in proliferation rate between CADASIL and control vascular smooth muscle cells are related to increased TGFbeta expression. J. Cell. Mol. Med. 22, 3016-3024.

Pankiv, S., Clausen, T.H., Lamark, T., Brech, A., Bruun, J.A., Outzen, H., Overvatn, A., Bjorkoy, G., Johansen, T., 2007. p62/SQSTM1 binds directly to Atg8/LC3 to facilitate degradation of ubiquitinated protein aggregates by autophagy. J. Biol. Chem. 282, 24131-24145.

Prakash, N., Hansson, E., Betsholtz, C., Mitsiadis, T., Lendahl, U., 2002. Mouse Notch 3 expression in the pre- and postnatal brain: relationship to the stroke and dementia syndrome CADASIL. Exp. Cell Res. 278, 31-44.

Rubinsztein, D.C., Cuervo, A.M., Ravikumar, B., Sarkar, S., Korolchuk, V., Kaushik, S. Klionsky, D.J., 2009. In search of an "autophagomometer". Autophagy 5, 585-589.

Ruchoux, M.M., Maurage, C.A., 1997. CADASIL: cerebral autosomal dominant arteriopathy with subcortical infarcts and leukoencephalopathy. J. Neuropathol. Exp. Neurol. 56, 947-964.

Ruchoux, M.M., Chabriat, H., Bousser, M.G., Baudrimont, M., Tournier-Lasserve, E., 1994. Presence of ultrastructural arterial lesions in muscle and skin vessels of patients with CADASIL. Stroke 25, 2291-2292.

Seibenhener, M.L., Babu, J.R., Geetha, T., Wong, H.C., Krishna, N.R., Wooten, M.W. 2004. Sequestosome $1 /$ p62 is a polyubiquitin chain binding protein involved in ubiquitin proteasome degradation. Mol. Cell. Biol. 24, 8055-8068.

Tai, S., Hu, X.Q., Peng, D.Q., Zhou, S.H., Zheng, X.L., 2016. The roles of autophagy in vascular smooth muscle cells. Int. J. Cardiol. 211, 1-6.

Takahashi, K., Adachi, K., Yoshizaki, K., Kunimoto, S., Kalaria, R.N., Watanabe, A., 2010 Mutations in NOTCH3 cause the formation and retention of aggregates in the endoplasmic reticulum, leading to impaired cell proliferation. Hum. Mol. Genet. 19, 79-89.

Terman, A., Gustafsson, B., Brunk, U.T., 2007. Autophagy, organelles and ageing. J. Pathol. 211, 134-143.

Tikka, S., Ng, Y.P., Di Maio, G., Mykkanen, K., Siitonen, M., Lepikhova, T., Poyhonen, M., Viitanen, M., Virtanen, I., Kalimo, H., Baumann, M., 2012. CADASIL mutations and shRNA silencing of NOTCH3 affect actin organization in cultured vascular smooth muscle cells. J. Cereb. Blood Flow Metab. 32, 2171-2180.

Tikka, S., Baumann, M., Siitonen, M., Pasanen, P., Poyhonen, M., Myllykangas, L., Viitanen, M., Fukutake, T., Cognat, E., Joutel, A., Kalimo, H., 2014. CADASIL and CARASIL. Brain Pathol. 24, 525-544.

Viitanen, M., Sundstrom, E., Baumann, M., Poyhonen, M., Tikka, S., Behbahani, H., 2013. Experimental studies of mitochondrial function in CADASIL vascular smooth muscle cells. Exp. Cell Res. 319, 134-143.

Wang, W., Prince, C.Z., Mou, Y., Pollman, M.J., 2002. Notch3 signaling in vascular smooth muscle cells induces c-FLIP expression via ERK/MAPK activation. Resistance to Fas ligand-induced apoptosis. J. Biol. Chem. 277, 21723-21729.

Wang, J., Whiteman, M.W., Lian, H., Wang, G., Singh, A., Huang, D., Denmark, T., 2009. A non-canonical MEK/ERK signaling pathway regulates autophagy via regulating Beclin 1. J. Biol. Chem. 284, 21412-21424.

Wibo, M., Poole, B., 1974. Protein degradation in cultured cells. II. The uptake of chloroquine by rat fibroblasts and the inhibition of cellular protein degradation and cathepsin B1. J. Cell Biol. 63, 430-440.

Zhang, L., Sheng, R., Qin, Z., 2009. The lysosome and neurodegenerative diseases. Acta Biochim. Biophys. Sin. (Shanghai) 41, 437-445.

Zhou, Y.Y., Li, Y., Jiang, W.Q., Zhou, L.F., 2015. MAPK/JNK signalling: a potential autophagy regulation pathway. Biosci. Rep. 35. 